\title{
Detection of Giardia lamblia Cysts in Surface Waters of Rasht City, Iran
}

\author{
Elham Saeedi', Nematollah Jonaidi Jafari², Ali Salehzadeh ${ }^{1 *}$ \\ ${ }^{1}$ Department of Biology, Rasht Branch, Islamic Azad University, Rasht, Iran; ${ }^{2}$ Health Research Center, Baqiyatallah \\ University of Medical Sciences, Tehran, Iran
}

Received Feb 11, 2018; Accepted Feb 21, 2018

\begin{abstract}
Introduction: Giardia lamblia is a protozoan parasite with universal distribution in human populations. This infections transfer to human via contaminated foods and waters with Giardia cysts. The Knowledge on the incidence of this agent in the potential infection sources can provide valuable information for control and the spread of this parasite to human communities. This study was aimed to isolate and identify the Giardia lamblia cysts in the surface waters of Rasht city, Guilan province, north of Iran with microscopy and PCR assay. Methods: This cross-sectional study was performed on 45 samples of surface waters collected from rivers and wetlands in the vicinity of Rasht city. The samples were concentrated using nitrocellulose membrane filters, and the sediments were examined for Giardia cysts by microscopy with a magnification of 1000 X. Also, DNA was extracted from the sediments, and the heat shock protein gene of G. lamblia was amplified. Results: From 45 samples, 33.33\% and $40 \%$ were positive by microscopy and PCR, respectively. Conclusion: In comparison with the standard microscopic method, PCR showed more sensitivity for detection of G. lamblia cysts in water samples. J Med Microbiol Infec Dis, 2018, 6 (1): 812.
\end{abstract}

Keywords: Giardia lamblia Cysts, Surface Waters, PCR, Rasht.

\section{INTRODUCTION}

Giardia lamblia, an intestinal flagellate protozoan, is the causative agent of one of the most common human parasitic infections worldwide known as giardiasis. It is estimated that 200 million people in Asia, Africa, and Latin America are infected with this parasite [1], and approximately, 500,000 new cases of the disease are reported in children annually [2].

Giardia lamblia cysts are highly pathogenic to humans; in a clinical study conducted on volunteers, ingestion of gelatin capsules containing 10 Giardia cysts caused giardiasis [3]. Symptoms of giardiasis are variable and range from no signs to chronic diarrhea, malnutrition, and weight loss [4]. In Iran, the diagnosis of G. lamblia is based on detection of G. lamblia cysts by microscopy in feces, which lacks the required sensitivity when the parasite is scanty [5]. Due to the intermittent shedding of cysts, microscopic examination of a single stool specimen has a low sensitivity of $46 \%$ [6]. Hence, at least three fecal samples should be taken and examined over a 3-5 day period to achieve 94\% accuracy in diagnosing Giardia cases [7]. In 1952, Filice differentiated Giardia duodenalis, Giardia morris, and Giardia argilis by the mean body size and the measurement of the dimensions of Giardia trophozoites [8]. In comparative studies on staining methods of Giardia cysts, trichrome staining showed to be the most sensitive approach [9]. In developing countries, pathogenic water-borne parasites of the gastrointestinal tract, including Entamoeba histolytica, G. lamblia, and Cryptosporidium parvum are frequent causes of human death, especially among children [10]. These parasites are the most common infectious agents worldwide [11]. Water is not a suitable medium for the growth of Giardia, but a high potential environment for spread and transmission of this parasite. Despite the refinement of water resources, some cysts can remain in it and survive for a long time [12]. The presence of G. lamblia cysts in water resources can cause outbreaks, especially during catastrophes such as flood and earthquakes. Several studies are annually conducted worldwide to screen for waterborne infectious agents. The obtained data can play a crucial role in the control of these infectious agents. Regarding the importance of rapid detection of G. lamblia cysts, this study was conducted for comparison of microscopy and PCR methods to identify $G$. lamblia cysts in surface waters of Rasht city, Guilan province, Iran.

\section{MATERIAL AND METHODS}

The study area and sample collection. Rasht city is located in Guilan province of Iran with $37^{\circ} 16^{\prime} 51^{\prime \prime} \mathrm{N}$ $49^{\circ} 34^{\prime} 59^{\prime \prime} \mathrm{E}$ coordinates and a mean elevation of $5 \mathrm{~m}$ above the sea level with an annual rainfall of above $1000 \mathrm{~mm}$ (Fig. 1). Amounts of one liter of water were collected at a depth of $\approx 30 \mathrm{~cm}$ from 12 rivers and 8 wetlands near Rasht city

\section{${ }^{*}$ Correspondence: Ali Salehzadeh}

Department of Biology, Rasht Branch, Islamic Azad University, Rasht, Iran, 4138845439.

Email: Salehzadeh@iaurasht.ac.ir

Tel: +98 (13) $33424094 \quad$ Fax: +98 (13) 33447060 


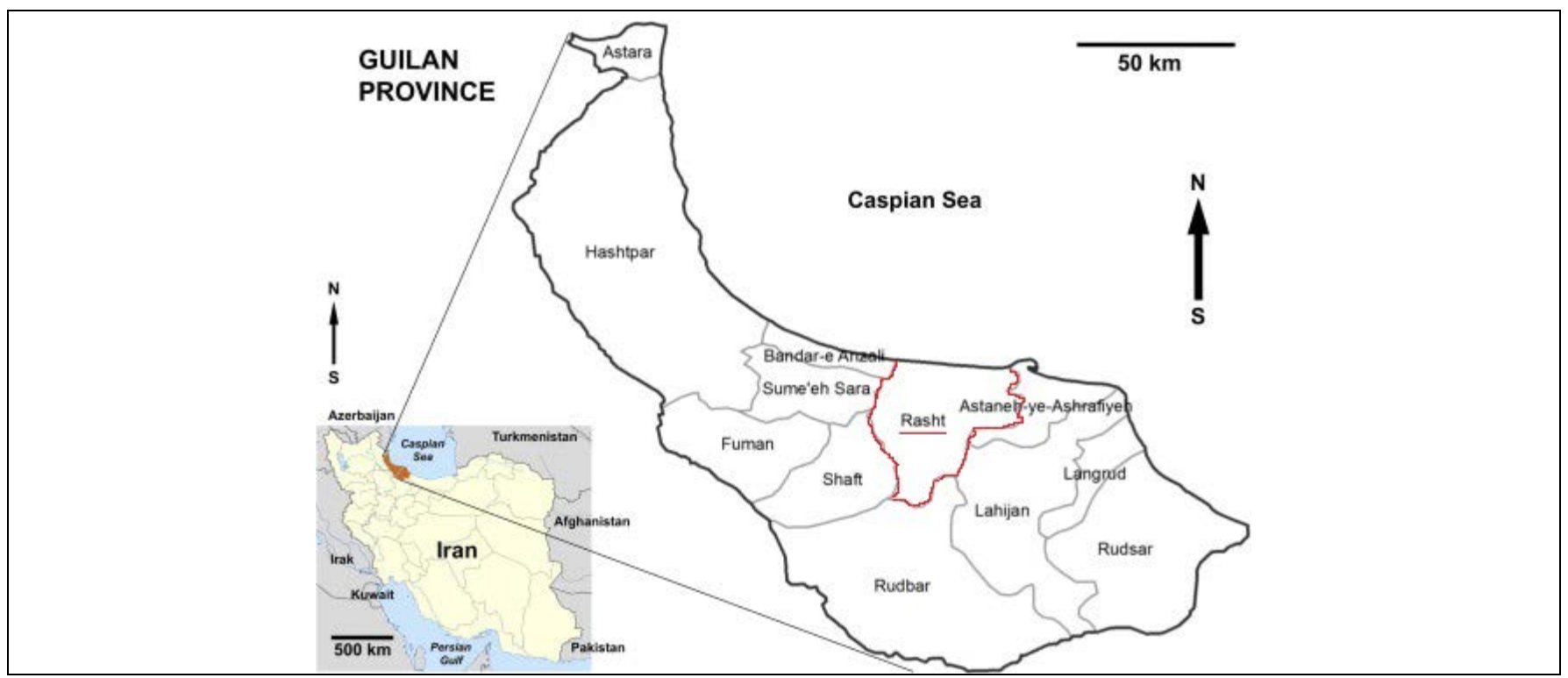

Fig. 1. The geographical location of Rasht city in Guilan province, Iran

during October to November 2014. All the samples were kept at $4^{\circ} \mathrm{C}$ and were analyzed within $48 \mathrm{~h}$.

Sample processing and preparation. Water samples were filtered using $0.2 \mu \mathrm{m}$ pore size qualitative Whatman filter papers (Sigma- Aldrich, Missouri, United States). The filter papers were washed with PBS buffer and centrifuged at $10000 \mathrm{rpm}$ for $15 \mathrm{~min}$. The sediments were stained with Lugol and examined for Giardia cysts with $1000 \mathrm{X}$ magnification of microscopy

DNA extraction and PCR. A freeze and thaw method with 15 cycles of $3 \mathrm{~min}$ at $-81^{\circ} \mathrm{C}$ and $100^{\circ} \mathrm{C}$, alternatively was performed to rupture the wall of the cysts in sediments. The phenol-chloroform method was used to extract DNA from sediments as described by others [13]. For molecular diagnosis of $G$. lamblia, a 350 bp fragment of heat shock protein gene was amplified with the primers hspF 5'-GCATGTCGTCAGTATAGGCG-3' and hspR 5'-

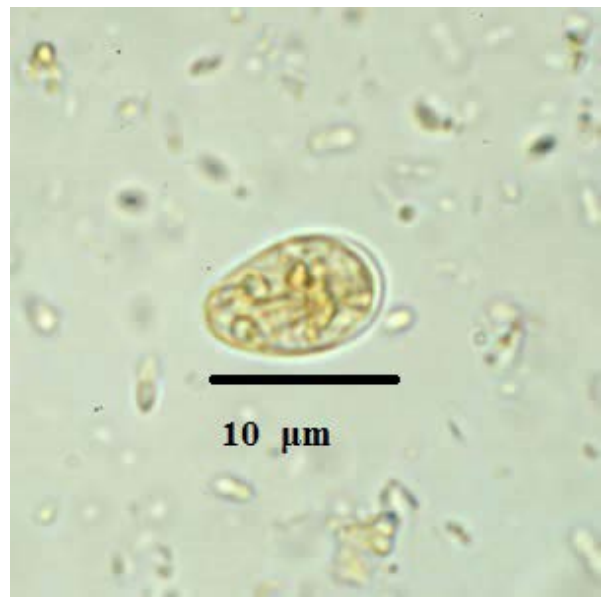

Fig. 2. A Giardia cysts recovered from a concentrated water sample
GCTTCACTGACTCGGCCTTA-3 designed in this study. The master mix for the PCR included $3 \mu \mathrm{l}$ of 10x PCR buffer, $2.5 \mathrm{mM}$ of $\mathrm{MgCl}_{2}, 3 \mu \mathrm{l}$ of $10 \mathrm{mM}$ dNTPs, $0.5 \mu \mathrm{l}$ of Taq ( $5 \mathrm{u} / \mu \mathrm{l})$ DNA Polymerase (CinnaGen, Tehran, Iran), 1 $\mu \mathrm{l}$ of the forward and reverse primers $(10 \mathrm{pmol}), 3 \mu \mathrm{l}$ of DNA template, and $12.5 \mu$ of double distilled water to make the final reactions $25 \mu \mathrm{l}$.

The PCR amplification consisted a single initial denaturation step at $94^{\circ} \mathrm{C}$ for 4 min followed by 35 cycles of $30 \mathrm{sec}$ at $94^{\circ} \mathrm{C}, 30 \mathrm{sec}$ at $47^{\circ} \mathrm{C}$, and $30 \mathrm{sec}$ at $72^{\circ} \mathrm{C}$, with a final extension step at $72^{\circ} \mathrm{C}$ for $5 \mathrm{~min}$. The amplified samples were run on a $1.5 \%$ agarose gel and visualized under a UV transilluminator. The DNA from Giardia cysts isolated from the stool samples of giardiasis patients by percoll gradient centrifugation protocol and distilled water were included as positive and negative controls, respectively.

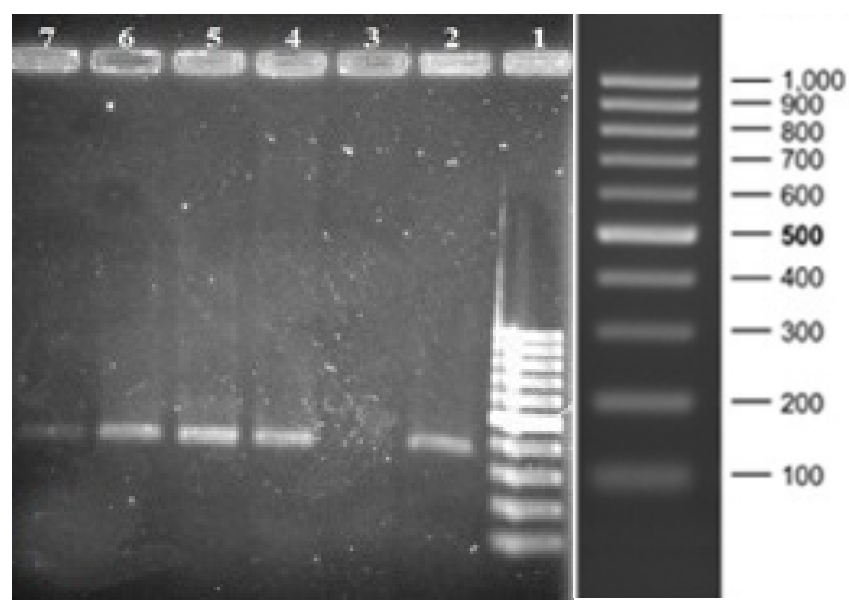

Fig 3. Detection of Giardia spp. in surface waters by PCR amplification of a $350 \mathrm{bp}$ fragment of heat shock protein gene. Lane 1, 100 bp ladder (CinnaGen, Tehran, Iran); lane 2, positive control; lane 3, negative control; lanes 4 to 7, DNA from surface waters 
Table 1. Positive concentrated water samples in different sampling sites

\begin{tabular}{c|cccc}
\hline Sample number & Sampling site & Number of collected samples & Microscopy & PCR \\
\hline $\mathbf{1}$ & Taleshan river bridge & 1 & + & + \\
$\mathbf{2}$ & Taleshan river bridge & 1 & + & + \\
$\mathbf{3}$ & Barban river & 2 & - & + \\
$\mathbf{4}$ & Khubak river & 2 & + & + \\
$\mathbf{5}$ & Khomamrud & 1 & + & + \\
$\mathbf{6}$ & Khomamrud & 3 & + & + \\
$\mathbf{7}$ & Pasikhan river & 2 & + & + \\
$\mathbf{8}$ & Sufian siah river & 2 & + & + \\
$\mathbf{9}$ & Jafar abad river & 1 & + & + \\
$\mathbf{1 0}$ & Jafar abad river & 2 & + \\
$\mathbf{1 1}$ & Nyshavandan river -Daroosazi & 2 & + \\
$\mathbf{1 2}$ & Nyshavandan river -Daroosazi & 1 & + & + \\
$\mathbf{1 4}$ & Eynak wetland & 1 & + \\
$\mathbf{1 5}$ & Eynak wetland & 2 & + \\
$\mathbf{1 6}$ & Ahmad Goorab & 1 & + \\
$\mathbf{1 8}$ & Ahmad Goorab & 2 & + \\
\end{tabular}

\section{RESULTS}

Out of a total of 45 sediments from surface waters, 15 (33.33\%) were positive for Giardia spp. by microscopy with the cysts appearing in brown color in Lugol-stained smears (Fig. 2). The PCR yielded the expected band in 18 (40\%) of the specimens (Fig. 3). The details of the water samples and microscopy and PCR assay are reflected in Table 1.

\section{DISCUSSION}

Giardia lamblia is a common parasitic cause of diarrhea, particularly in children leading to their malnutrition and delayed growth. Laboratory diagnosis is frequently based on detection of cysts and trophozoites of the parasite by direct wet mount microscopy [14]. Microscopical examination of three stool samples is considered as the "gold standard" for diagnosis of G. lamblia infection in humans, but the sensitivity of this method is low (46\%) even after multiple examinations [15]. PCR assays for detection of G. lamblia have proven to be very useful with the advantages of reduced labor and time consumption required for diagnosis [16]. When compared with direct microscopy method, PCR with a sensitivity of $100 \%$ and specificity of $94 \%$ can be utilized as an alternative method for diagnosis of giardiasis [17].

Contamination of water with Giardia cysts is directly related to the health and economic status of the community, especially in areas in which the wastewaters are disposed in the environment without any treatment. This problem primarily is more evident in the rainy seasons. In such regions, runoff waters transfer the cysts to surface waters and increase the risk of disease transmission if they are not controlled [18]. Mostly, surface waters are used for domestic consumption after treatment with disinfecting agents. Chlorination is one of the most commonly used methods in water treatment [19]. However, due to the high resistance of protozoa (including Giardia cysts) to disinfection, they should be filtered out rather than just treated through tap water chlorination [20]. The use of sand or diatomaceous filters can remove the majority of protozoa from contaminated waters. There are reports of the isolation of Giardia cysts from drinking waters by filtration [21]. Epidemiological studies on water resources can be valuable during outbreaks of giardiasis. In 1974, Giardia cysts were detected following the incidence of giardiasis in water resources in New Jersey, USA [22]. Tracking and detection of Giardia cysts in water samples involves three steps; concentration, purification, and recovery phases. Today, filtration is used in the majority of studies to concentrate collected water samples. Microfilters of $0.1 \mu \mathrm{m}$ or larger pore size are considered as the most appropriate filters in slow sand filtration and precoat filtration [23].

Floatation methods using zinc sulfate, sucrose, percoll/sucrose, and potassium citrate solutions are used for the purification and recovery of Giardia cysts from concentrated water samples [24]. In this study, we used percoll/sucrose method to recover the cysts [25]. Before the 1990s, most studies used microscopy and IFA for the detection of Giardia cysts in water resources [26]. In 1979, IFA method was introduced for the detection of Giardia. In IFA test, Giardia cysts are detected using fluorescent monoclonal antibodies following a concentration step [27]. Today, this method is rarely used as the efficacy of recovery is affected by water quality, especially turbidity of water. Moreover, IFA method is time-consuming, tedious and expensive and requires experienced and skilled staff.

With the advent of molecular methods, more useful tools were developed for detection of protozoa in contaminated waters. Abbaszadegan and colleagues (1991) detected Giardia in water samples by a cDNA probe [28]. In subsequent studies, the sensitivity level increased to detection of a DNA equivalent to a single Giardia cyst by a PCR assay [29]. The advantages of PCR technique included the distinction between live and dead cysts as well as identification of, and differentiation between Giardia species [30, 31]. In this study, with specific primers for the heat shock protein gene of $G$. lambelia, we reported a contamination rate of $40 \%$ in surface waters of Rasht city. Using IFA, LAMP, and PCR for the detection of Giardia cysts, Mahmoudi et al. (2013) reported 37.5\% contamination in two rivers of Guilan province, which is almost similar to our results [32]. In a study in Brazil by Fernandes and colleagues (2011), PCR detected Giardia 
duodenale in $41.6 \%$ of surface waters, agricultural waters, and sewage [33]. Monitoring of hygienic principles to prevent the infiltration of infectious agents into water resources can result in significant reduction of water supplies contamination. In developed countries, e.g., Germany and Finland, the contamination rate of water resources with Giardia cysts was reported to be $4.2 \%$ and $13.7 \%$, respectively $[34,35]$. Guilan province is a significant location for agricultural activities in Iran and comprises a considerable proportion of fertile lands of the country. In this region, agriculture systems, mostly traditional, use surface waters sources for irrigation, which may contaminate many products leading to a variety of foodborne diseases among the consumers [36]. In Iran and Turkey, several studies reported contamination of fruits and vegetables with Giardia cysts [37, 38, 39]. The results of this study indicate a significant presence of Giardia cysts in surface waters in Rasht. Given the importance of this contamination as a hygienic problem for residents of Rasht city, we recommend treatment of human wastewater as the most crucial sanitary measure to avoid contamination of surface waters with parasitic cysts.

The staining method was efficient for the diagnosis of Giardia cysts in concentrated surface water samples. In the detection of $G$. lamblia cysts from water samples, PCR was more sensitive and more specific than microscopy method. Considering the widespread use of water resources for agricultural activities, monitoring of sanitary measures for pathogen control such as preventing human sewage from entering into water sources, is highly recommended.

\section{ACKNOWLEDGEMENT}

The authors would like to acknowledge the Baqiyatallah University of Medical Sciences for material support of this research.

\section{CONFLICT OF INTEREST}

The authors declare that there are no conflicts of interest associated with this manuscript.

\section{REFERENCES}

1. Wolfe MS. Giardiasis. Clin Microbiol Rev. 1992; 5 (1): 93100.

2. Thompson R. The zoonotic significance and molecular epidemiology of Giardia and giardiasis. Vet Parasitol. 2004; 126 (1-2): 15-35.

3. Rajurkar M, Lall N, Basak S, Mallick S. A Simple Method for Demonstrating the Giardia Lamblia Trophozoite. J Clin Diagn Res. 2012; 6 (9): 1492-4.

4. Rendtorff RC. The Experimental Transmission of Human Intestinal Protozoan Parasites II. Giardia Lamblia Cysts GWEN in Capsules. Am J Hyg. 1954; 59 (2): 209-20.

5. Flanagan P. Giardia--diagnosis, clinical course and epidemiology. A review. Epidemiol Infect. 1992; 109 (1): 1-22.

6. Jahan N, Khatoon R, Ahmad S. A Comparison of Microscopy and Enzyme Linked Immunosorbent Assay for Diagnosis of
Giardia lamblia in Human Faecal Specimens. J Clin Diagn Res. 2014; 8 (11): DC04-DC06.

7. Weitzel TS, Dittrich S, Mohl I, Adusu E, Jelinek T. Evaluation of seven commercial antigen detection tests for Giardia and Cryptosporidium in stool samples. Clin Microbiol Infect. 2006; 12 (7): 656-59.

8. Filice FP. Studies on the cytology and life history of a Giardia from the laboratory rat. Univ Calif Publ Zoolo. 1952; 57: 53-146.

9. Nieminski EC, Schaefer F, Ongerth JE. Comparison of two methods for detection of Giardia cysts and Cryptosporidium oocysts in water. Appl Environ Microbiol. 1995; 61 (5): 1714-9.

10. Haque R. Human Intestinal Parasites. J Health Popul Nutr. 2007; 25 (4): 387-91.

11. Cráun GF. Waterborne giardiasis. Giardiasis. 1990: 267-93.

12. Rose JB, Haas CN, Regli S. Risk assessment and control of waterborne giardiasis. Am J Public Health. 1991; 81 (6): 709-13.

13. Ogram A, Sayler G, Barkay T. The extraction and purification of microbial DNA from sediments. J Microbiol Methods. 1987; 7 (2): 56-67.

14. Ian H. McHardy IH, Wu M, Shimizu-Cohen R, Couturier MR, Romney M. Detection of Intestinal Protozoa in the Clinical Laboratory. J Clin Microbiol. 2014; 52 (3): 712-20.

15. Barazesh A, Majidi J, Fallah E, Jamali R, Abdolalizade J, Gholikhani R. Designing of enzyme linked immunosorbent assay (ELISA) kit for diagnosis copro-antigens of Giardia lamblia. Afri J Biotechnol. 2010; (31): 5025-27.

16. Schuurman T, Lankamp P, Van Belkum A, Kooistra-Smid M, Van Zwet A. Comparison of microscopy, real-time PCR and a rapid immunoassay for the detection of Giardia lamblia in human stool specimens. Clin Microbiol Infect. 2007; 13 (12): 1186-91.

17. Beyhan YE, Cengiz ZT. Comparison of microscopy, ELISA, and real-time PCR for detection of Giardia intestinalis in human stool specimens. Turk J Med Sci. 2017; 47: 1295-9.

18. WHO. Guidelines for drinking-water quality: Surveillance and control of community supplies: World Health Organization, Geneva; 1997. 238.

19. Serodes J, Rodriguez M. Method of predicting residual chlorine in water supply systems. US Patent. 1997; 5: 504-675.

20. Betancourt WQ, Rose JB. Drinking water treatment processes for removal of Cryptosporidium and Giardia. Vet parasitol. 2004; 126 (1): 219-34.

21. Wallis P, Erlandsen S, Isaac-Renton J, Olson M, Robertson W, Van Keulen H. Prevalence of Giardia cysts and Cryptosporidium oocysts and characterization of Giardia spp. isolated from drinking water in Canada. Appl and environ microbiol. 1996; 62 (8): 2789-97.

22. Rendtorff R. Giardia in water. Ann of Intern Med. 1975; 82 (2): $280-1$.

23. Jacangelo JG, Rhodes Trussell R, Watson M. Role of membrane technology in drinking water treatment in the United States. Desalination. 1997; 113 (2): 119-27.

24. Zajac AM, Johnson J, King SE. Evaluation of the Importance of Centrifugation as a Component of Zinc Sulfate Fecal Flotation Examinations. J Am Anim Hosp Assoc. 2002; 38: 221-4. 
25. LeChevallier MW, Norton WD, Lee RG. Evaluation of a method to detect Giardia and Cryptosporidium in water. ASTM Spec Tech. 1991 (1102): 483-98.

26. Nieminski EC, Schaefer F, Ongerth JE. Comparison of two methods for detection of Giardia cysts and Cryptosporidium oocysts in water. Appl Environ Microbiol. 1995; 61 (5): 1714-9.

27. Visvesvara G, Healy G, editors. The possible use of an indirect immunofluorescent test using axenically grown Giardia lamblia antigens in diagnosing giardiasis. Proceedings, symposium on waterborne transmission of giardiasis US Environmental Protection Agency, Cincinnati; 1979.

28. Abbaszadegan M, Gerba C, Rose J. Detection of Giardia cysts with a cDNA probe and applications to water samples. Appl Environ Microbiol. 1991; 57 (4): 927-31.

29. Abbaszadegan M, Huber MS, Gerba CP, Pepper IL. Detection of viable Giardia cysts by amplification of heat shockinduced mRNA. Appl Environ Microbiol. 1997; 63 (1): 324-8.

30. Mahbubani M, Bej A, Perlin M, Schaefer F, Jakubowski W, Atlas R. Detection of Giardia cysts by using the polymerase chain reaction and distinguishing live from dead cysts. Appl Environ Microbiol. 1991; 57 (12): 3456-61.

31. Weiss JB, van Keulen $H$, Nash TE. Classification of subgroups of Giardia lamblia based upon ribosomal RNA gene sequence using the polymerase chain reaction. Mol Biochem Parasitol. 1992; 54 (1): 73-86.

32. Mahmoudi M-R, Kazemi B, Mohammadiha A, Mirzaei A, Karanis P. Detection of Cryptosporidium and Giardia (oo)cysts by IFA, PCR and LAMP in surface water from Rasht, Iran. Trans R Soc Trop Med Hyg. 2013; 107 (8): 511-7.
33. Fernandes LN, De Souza PP, De Araujo RS, Razzolini MTP, Soares RM, Sato MIZ. Detection of assemblages A and B of Giardia duodenalis in water and sewage from Sao Paulo state, Brazil. J Water Health. 2011; 9 (2): 361-7.

34. Gallas-Lindemann C, Sotiriadou I, Plutzer J, Karanis P. Prevalence and distribution of Cryptosporidium and Giardia in wastewater and the surface, drinking and ground waters in the Lower Rhine, Germany. Epidemiol Infect. 2013; 141 (1): 9-21.

35. Hörman A, Rimhanen-Finne R, Maunula L, von Bonsdorff C-H, Torvela N, Heikinheimo A. Campylobacter spp., Giardia spp., Cryptosporidium spp., noroviruses, and indicator organisms in surface water in southwestern Finland, 2000-2001. Appl Environ Microbiol. 2004; 70 (1): 87-95.

36. Jung Y, Jang H, Matthews KR Effect of the food production chain from farm practices to vegetable processing on outbreak incidence. Microb Biotechnol. 2014; 7 (6): 517-27.

37. Nazemi S, Raei M, Amiri M, Chaman R. Parasitic contamination of raw vegetables in Shahroud, Semnan. Zahedan J Res Med Sci. 2012; 14 (8): 84-6.

38. Olyaei A, Hajivandi L. Parasitological contamination of markets and farms in vegetables consumed in southern Iran. Glob Vet. 2013; 10 (3): 327-31.

39. Erdog rul Ö, Şener H. The contamination of various fruit and vegetable with Enterobius vermicularis, Ascaris eggs, Entamoeba histolyca cysts and Giardia cysts. Food Control. 2005; 16 (6): 557-60. 